\title{
Defect reduction in a capacitor manufacturing process through Six Sigma concept: A case study
}

\author{
Ravi Shankar Raman ${ }^{a, b^{*}}$ and Yadavalli Basavaraj ${ }^{\mathrm{c}}$
}

${ }^{a}$ Associate Professor, Mechanical Engineering Department, ABES Engineering College, Ghaziabad, India

${ }^{b}$ Research Scholar Visvesvaraya Technological University, Belgaum,India

${ }^{c}$ Professor \& Head in ME department, Ballari Institute of Technology \& Management, Ballari, India

CH R O I CLE A B S T RACT

Article history:

Received: October 14, 2018

Received in revised format: No-

vember 25,2018

Accepted: November 25, 2018

Available online:

November 26, 2018

Keywords:

Six Sigma

DMAIC Methodology

Capacitor

Pareto chart

Cause and effect diagram
In the present scenario, the Six Sigma tools and techniques are used by various manufacturing industries, exporting industries and even service organizations. It focuses on improving the quality of the products, cutting down the extra costs, reducing the variations and satisfying the customers. This case study follows the Six Sigma tools called DMAIC methodology to identify and analyze various root causes of the capacitors rejection problems, which influence the performance of the company and suggests solutions to counter with it. The issue not only causes financial loss to the company but also hinders future growth in form of customer dissatisfaction. The results of the implementation indicate significant improvement in the quality of the product and cost reduction.

C 2019 by the authors; licensee Growing Science, Canada

\section{Introduction}

The Six Sigma Methodology is one of the strategies which helps in the reduction of the existing number of defects of the order of 3.4 defects per million opportunities in the design of the product, production and the governance process (Schroeder et al., 2009). The Six Sigma is a systematic and organized problem-solving tool for strategic system, new product and service development that depends on the application of the scientific techniques for the improvement of the output variables. Six-sigma kicked off, as a quality improvement method, in 1970's when the Motorola factory in the United States was overtaken by a Japanese company (Deshmukh \& Chavan, 2012). In the mid of 1980's, the revolution was started and the Six-Sigma has been used for the regular betterment of the process.

Six-Sigma follows a systematical approach like DMAIC- (Define, Measure, Analyze, Improve and Control) methodology that targets the quantifiable problems by promoting continuous improvement, it is a statistical and scientific approach. This cyclic process uses technology and measurement to eliminate the unproductive steps as discussed by Kaushik and Khanduja (2009). According to More and Pawar (2015) six sigma is a business mindset to improve the quality of the products and the processes.

* Corresponding author.

E-mail address: ravi.raman21@gmail.com (R. S. Raman)

C 2019 by the authors; licensee Growing Science, Canada doi: $10.5267 /$ j.msl.2018.11.014 
Thus, to increase the profitability of the company the primary factors are quality and productivity. The advantages of using Six-Sigma area diverse workforce with varying levels of education, a unified workforce where everyone feels like a part of the greater whole, a standard procedure for any process and increased teamwork (Gupta \& Garg, 2014). According to Kuptasthien and Boonsompong (2011), there is a relationship between the process variability and product specification. Hence using statistical tools one can eliminate this variability or reduce it significantly making process efficient and product better (De Mast \& Lokkerbol, 2012).

In this study, the problem is identified by using the tools of Six Sigma. The first step is to identify the root-cause problems, for this we have to prepare a fishbone diagram and after study the fishbone diagram we analyze all root causes through a process map, which helps to locate the precise locations, accurately. Accordingly during the last six months, reports have received from various departments, for analyzing the weight age of each problem along with a brainstorming activity with their respective agents and formulate the roadmap of a present capacitor-manufacturing problem. This study helps in identifying the root causes of the problem in the capacitor manufacturing and provides the practical solution to counter each one of them. This is the first initiative taken to find the root cause of the capacitor-manufacturing problem and analyze the rejected pieces and suggest a solution to reduce the defects using Six-Sigma.

\section{Six Sigma Approach}

Six Sigma includes a set of systematized techniques and tools where everyone knows what is expected and the way to contribute to organization. Sigma is a parameter which is used to measure the variation of any process effectively. It is also called as the data-driven procedure for improving the process. Six Sigma is a very powerful tool for analysis part of any process. Sir Bill Smith was the person who developed and introduced the six sigma in Motorola in 1986 with an aim to increase the total production by reducing variation in the processes (Gupta \& Kumar, 2014). The rigorous application of various statistical tools and techniques resulting in the enhanced existing level of sigma incorporates the fundamental principle of Six Sigma as shown by Matathil et al. (2012). The primary objective in this case study is to find the primary reason behind the existing defects using Six Sigma and suggest solutions.

\section{Methodology}

This study deals with the following processes:

\subsection{Define}

Define is the first phase of DMAIC methodology whose aim is to define and to identify the basic problems through the voice of customers, the voice of business, SIPOC, and process map. After this the customer requirements are identified which forms the foundation for Critical to Quality Characteristics (CTQs), these are the quality parameters which are critical for satisfying the customer's requirements. In this stage, the problem statement is clearly determined along with the project scope and role of team is also determined through this parameter. (Ng et al., 2014; Raman et al., 2017).

\subsection{Measure}

In this phase, we have to find the product characteristics that we wish to improve and map out the steps involved in it. For this, we have to check the measurement system record, the corresponding data and set the level of performance that we want to achieve in the process. To identify all the problems that we are currently facing we have used cause and effect diagram (Ping Yi et al., 2012). This is also referred as the Fishbone or Ishikawa diagram and the benefit is to help in identifying the causes of the problem. 


\subsection{Analyze}

In this phase, all the problems identified in the measure phase are considered. Brainstorming is performed to identify the root causes. By using the quality tools like Pareto Chart we can easily identify the root cause (Prashar, 2014). The reason for targeting the root cause is to find its effect on the process variation.

\subsection{Improve}

In this phase solutions to the major problems identified in the previous phase are implemented. One of the most important steps in this phase is to identify the key variables and to identify an effect for causing variation in the quality characteristics. The solution implemented in this stage must focus on keeping the existing process within the desired limit.

\subsection{Control}

In this phase a revision on the current process is performed by making the process standardized. Documenting of each process is executed and time is distributed according to the requirement of each process keeping in mind the productivity. After implementing the new process it is monitored till the system starts working smoothly. Implementing the new process is much easier than sustaining it hence monitoring becomes an integral part of this phase. Setting the new standards can help in countering this problem (Erbiyik \& Saru, 2015).

\section{Company background}

This case study is performed at Capacitor Industry in northern India which is a leading manufacturer of Plastic Film Capacitors with an installed capacity of 750 million pieces per annum. More than $60 \%$ of the sale goes into Lighting Industry. The company is also producing Film Foil and Metalized capacitors used in CFL applications. They are the only Indian manufacturer making Inductive Capacitors always competing with the imported capacitors. The customers were in need of more capacitor, for doing this they have to modify the plant layout and install more machines to increase their productivity in a better way.

\subsection{Define Phase}

The problem statement of our case study is "to reduce the Capacitor Rejection problems during the manufacturing process". The first and foremost step for implementing any six sigma project is to identify the problem as a business problem focusing on the budget, constraint and potential resources. The project goals must be defined clearly their critical process output and other factors which impact on the process and variations. To analyze the problem in detail an effective and dedicate members are chosen from different domains like a manager, engineer, technician, research scholar, and the operator. In this case study internal employs, workers are treated as customers. For defining and understanding the process boundaries, the primary focus is always on the customers. SIPOC is a process map that helps to identify the various key processes. It also helps in analyzing the effect of these input key factors on the output response and determines the start point of data collection. Fig. 1 shows the SIPOC diagram for the whole process of the company, which is the main focus of this research. This technique is also discussed by Fan et al. (2015) and Srinivasan et al. (2014). Through the idea of the voice of business or voice of internal employs from which we can determine the customers' needs and their expectations and convert them into a clear visible data (Ganguly, 2012). The SIPOC is presented in Table 1. In the logistics department of company, we have encountered $2.26 \%$ of the total capacitors which are rejected during the manufacturing of various stages due to various manufacturing defects. Since our monthly sales of capacitors is an average of 29000000 (pieces). So, 655400 (pieces.) are rejected during the manufacturing process. On an average, the total rejected capacitors are just wasted and go into scrap and this cannot be used further. Since the average selling price of per capacitor is Rs. 1.80/- and the total loss of the company is around 1179720 . Therefore we prepare a problem and need statement based 
on the voice of customers and voice of business as shown in Table 2 and finally formulate the critical to quality (CTQ).

Table 1

SIPOC

\begin{tabular}{|c|c|c|c|c|}
\hline Suppliers & Inputs & Process & Outputs & Customers \\
\hline Film, Aluminum foil and protective film & Winding machine setup, Roller setup & Winding & \multirow{11}{*}{$\begin{array}{c}\text { Capacitors are } \\
\text { produced of } \\
\text { range from } \\
5 \mathrm{~mm} \text { to } 37 \\
\mathrm{~mm} .\end{array}$} & Lighting \\
\hline manufacturers & Pressing machine & Pressing & & Industries \\
\hline Lead, Zinc and Tin wires manufacturers & Machine setup & Masking & & \multirow{9}{*}{$\begin{array}{c}\text { Electrical and } \\
\text { Electronic } \\
\text { Industries. }\end{array}$} \\
\hline & Spray machine Setup & Spraying & & \\
\hline Masking Tape manufactures & & De-Masking & & \\
\hline Pinching Tape manufactures & Welding machine setup & Welding \& Pinching & & \\
\hline \multirow[t]{2}{*}{ Epoxy and Wax powder Manufacturers } & Curing oven setup & Powder coating & & \\
\hline & & Marking \& cutting & & \\
\hline \multirow[t]{3}{*}{ Equipment suppliers } & Testing setup & Visual Inspection & & \\
\hline & Utility (power) & Quality Testing & & \\
\hline & Manpower assistants & Lead cut \& Packing & & \\
\hline
\end{tabular}

Table 2

Analysis of business case

VOB/VOC (Voice of business \&customer) Issue Statement

Need Statement
Rejection/Complaint rate is high (2.26\%)

Rejection rate / Complaint rate

To reduce the rejection rate /

To reduce the rate of complaint

Hence, from Table 2, we mainly focus on reducing the rejection rate as well as the complaint rate. In order to do the same, we need to lower the rejection rate by reducing the number of defects during capacitor manufacturing process. Thus, the Critical To Quality can be written as follows,

1. Total no. of rejected capacitors should not under 435000 per month.

2. Identify the importance of continuous quality enhancement at the lowest possible cost by means of automation.

Now, Revised the process map (Fig. 1) which shows different processes in a sequence manner to identify the flaws in the process and with the help of these flaws we can solve the problem with a better approach.
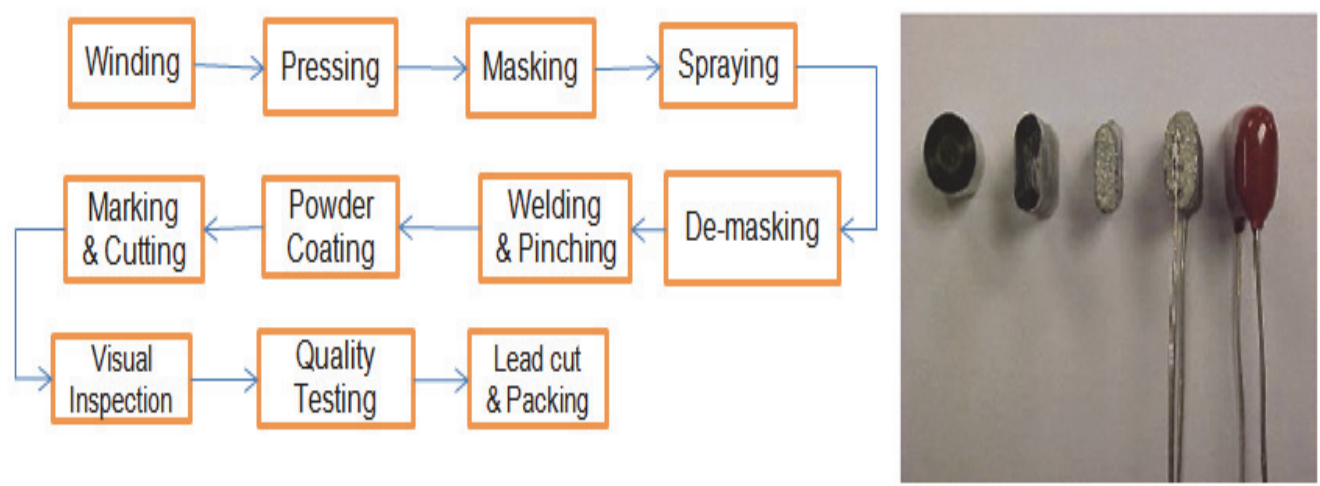

Fig. 1. Process Map

\subsection{Measure Phase}

After studing the whole process of capacitor's manufacturing, we found and analyzed different causes, which influence on the manufacturing process. These causes are the results of heavy rejection and these are coming from a brainstorming activity with different respective heads like Production, Quality, Logistics, etc. Now based on the inputs/causes obtained from brainstorming session we prepare the 
cause-effect diagram. The cause-effect diagram is also known as Fishbone diagram.It is a tool to show all the possible causes that impact on the manufacturing process for optimizing the research problem in terms of the overall effect (Jirasukprasert et al., 2014). Cause-and-Effect diagram as shown in Fig. 2 concludes that the challenges encountered by the company are out of tolerance rejection: Tan delta, Welding, Undip, Marking, Burr, Cavity. If the company utilizes its time and resources effectively then these rejection can be reduced significantly.

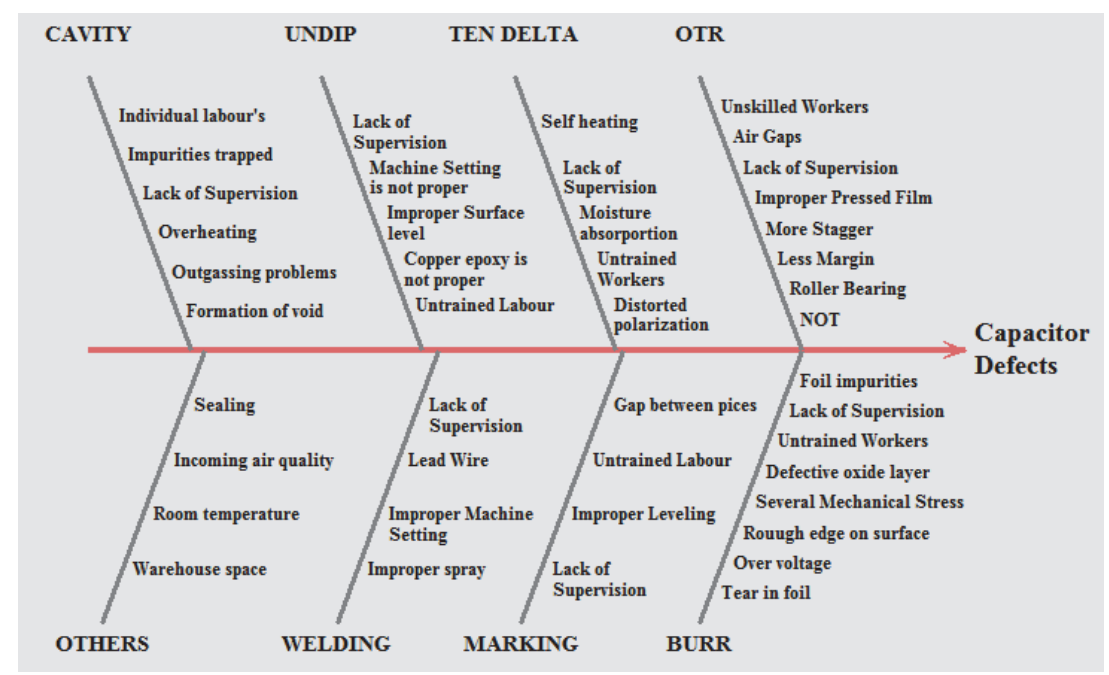

Fig. 2. Cause and Effect Diagram

\subsection{Analysis Phase}

The data was collected for the last six months, which show the weight age of each root causes impact on capacitor's rejection during production and losses in terms of company revenue as shown in Table 3. Now based on the above-collected data we draw the Pareto chart that helps to find out the most frequent root cause so that we can easily focus on that particular root cause and find the possible solution to counter it (Awaj et al., 2013). From the Pareto chart it is clearly identified that OTR,TD,WD and UD play a significant role which impacts the production and hence need to focus on minimizing them. If we focus on these 3 root causes and utilize major resources for reducing them then there is a possibility of reducing $3 / 4^{\text {th }}$ of the total losses incurred, bring our analysis closer to the Pareto principle i.e. $80 \%$ of the problems are caused due to the $20 \%$ of the causes.

\section{Table 3}

Analysis of root cause

\begin{tabular}{ccc}
\hline Root Cause & Weight age (\%) & Loss Fig. (INR) \\
\hline OTR & 36 & 229680 \\
Tan Delta(TD) & 18.7 & 119306 \\
Welding(WD) & 16.43 & 104823 \\
Undip(UD) & 7.2 & 45936 \\
Marking(MR) & 6.3 & 40194 \\
Burr(BR) & 5.6 & 35728 \\
Cavity(CV) & 5.4 & 34452 \\
Others & 4.3 & 27434 \\
\hline
\end{tabular}

\subsection{Improve Phase}

After analyzing all possible root causes, a number of possible solutions are suggested to overcome or reduce the losses during manufacturing of capacitors. The Solutions are suggested in consultation with other departments like production, quality, logistics etc. and the senior operators. It was our intention to make the solution feasible and economical (Simanova, 2015). The solutions are given in Table 4. 


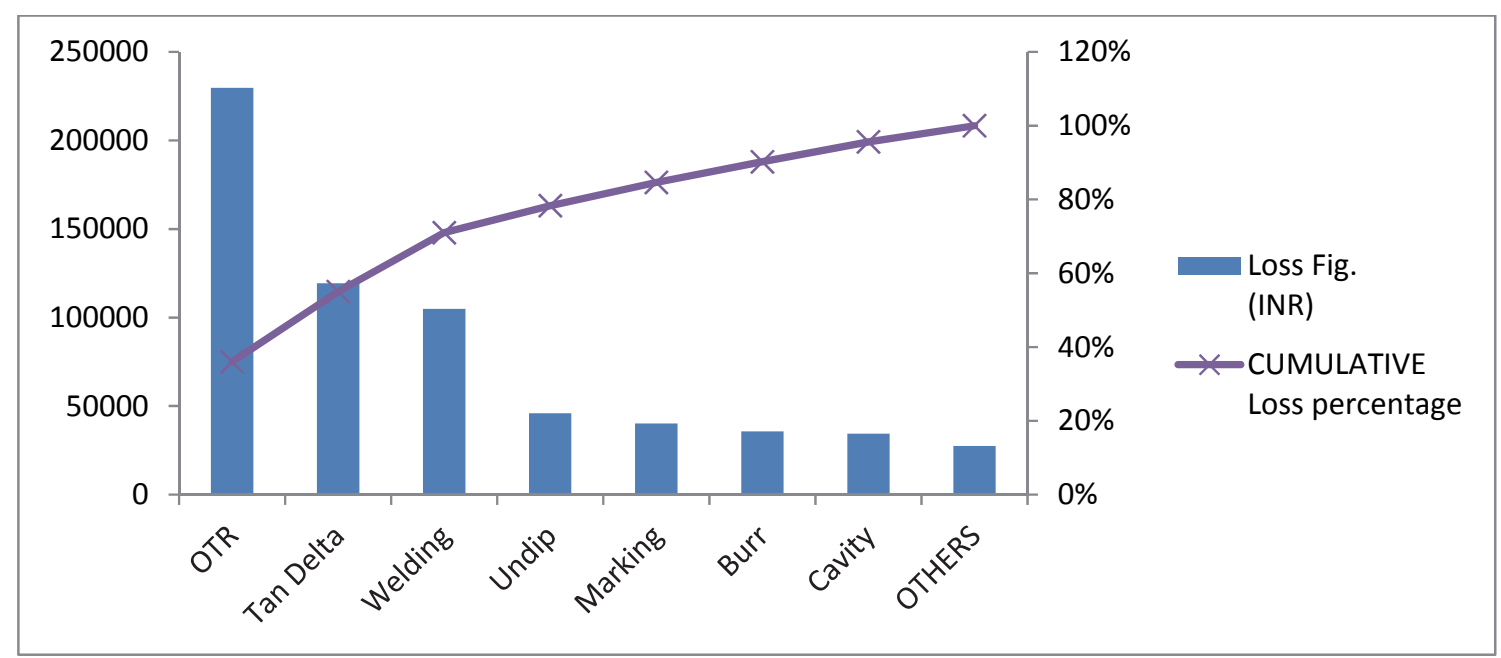

Fig. 3. Pareto chart

Table 4

The solution

\begin{tabular}{|c|c|c|c|}
\hline $\begin{array}{l}\text { Root } \\
\text { Cause }\end{array}$ & $\begin{array}{c}\text { Weight } \\
\text { age }\end{array}$ & Causes \& Effect & Proposed Solution \\
\hline OTR & $36 \%$ & $\begin{array}{ll}\text { 1. } & \text { Less Margin } \\
\text { 2. } & \text { More stagger value } \\
\text { 3. } & \text { Use of improper pressed Film } \\
\text { 4. } & \text { Use of less or more number of turns (NOT) } \\
\text { 5. } & \text { Air gap } \\
\text { 6. } & \text { Unskilled workers }\end{array}$ & $\begin{array}{l}\text { 1. Do's and Don'ts session of } 15 \text { minutes to be organized daily by the supervi- } \\
\text { sor before each shift. } \\
\text { 2. Install the LCD Monitors or Posters with continuous videos or photos of Do's } \\
\text { and Don'ts actions at the winding section. } \\
\text { 3. Each employee must be trained for a period of } 7 \text { days directly under the super- } \\
\text { visor regardless of employee's experience. } \\
\text { 4. Maintain proper roller movement and air gap. } \\
\text { 5. Maintain the stagger value \& free margin. } \\
\text { 6. Proper cleaning of rollers }\end{array}$ \\
\hline BURR & $5.6 \%$ & $\begin{array}{l}\text { 1. Rough edge on the surface in the form of small } \\
\text { metal particles. } \\
\text { 2. The weak point of the electrolytic film. } \\
\text { 3. Severe mechanical stress } \\
\text { 4. Application of over voltage } \\
\text { 5. Defective oxide layer } \\
\text { 6. Foil impurities } \\
\text { 7. Breaks or tears in the foil, and breaks or tears in } \\
\text { the separator film. }\end{array}$ & $\begin{array}{l}\text { 1. Do's and Don'ts session of } 15 \text { minutes to be organized daily by the supervisor } \\
\text { before each shift. } \\
\text { 2. Operator should be sufficiently trained. } \\
\text { 3.Proper control of raw material should be taken place } \\
\text { 3. Quality \& production supervisors should be ensure about the film before } \\
\text { feeding them into the machine. } \\
\text { 4. For proper implementation of the above idea, this should be converted into a } \\
\text { system } \\
\text { 5. Training to be provided to the operator should be according to process criti- } \\
\text { cality. }\end{array}$ \\
\hline $\begin{array}{l}\text { Tan } \\
\text { Delta } \\
\text { (TD) }\end{array}$ & $18.7 \%$ & $\begin{array}{l}\text { 1. The distorted polarization of the dielectric. } \\
\text { 2. Resolution and formation of the dielectric. } \\
\text { 3. Moisture absorption by the dielectric. } \\
\text { 4. Self-heating }\end{array}$ & $\begin{array}{l}\text { 1. Control and maintain the self-heating phenomena. } \\
\text { 2. Maintain the proper insulation resistance. } \\
\text { 3. The operator should be sufficiently trained for these particular problems. }\end{array}$ \\
\hline $\begin{array}{l}\text { Welding } \\
\text { (WD) }\end{array}$ & $16.43 \%$ & $\begin{array}{l}\text { 1.Excess spray } \\
\text { 2. Improper spray process } \\
\text { 3.Improper welding machine setting } \\
\text { 3. Improper lead wire attachment. } \\
\text { 4. Lack of welding knowledge. }\end{array}$ & $\begin{array}{l}\text { 1. Do's and Don'ts session of } 15 \text { minutes to be organized daily by the supervi- } \\
\text { sor before each shift. } \\
\text { 2. The operator should be sufficiently trained for welding process. } \\
\text { 3. Maintain the proper spray process. } \\
\text { 4. Maintain the proper welding machine setup before the operation. }\end{array}$ \\
\hline $\begin{array}{l}\text { Undip } \\
\text { (UD) }\end{array}$ & $7.2 \%$ & $\begin{array}{l}\text { 1. Copper epoxy is not proper. } \\
\text { 2. Improper Level. } \\
\text { 3. Improper setting of powder coating machine. } \\
\text { 4. Lack of skilled workers. }\end{array}$ & $\begin{array}{l}\text { 1. Do's and Don'ts session of } 15 \text { minutes to be organized daily by the supervisor } \\
\text { before each shift. } \\
\text { 2. Maintain the proper setting of the machine before operation. } \\
\text { 3. Maintain the uniform level. } \\
\text { 4. Proper training should be provided to workers. }\end{array}$ \\
\hline $\begin{array}{l}\text { Cavity } \\
(\mathrm{CV})\end{array}$ & 5.4 & $\begin{array}{l}\text { 1. Impurities trapped during manufacturing. } \\
\text { 2. Outgassing of the materials used, or chemical re- } \\
\text { actions as is when the packaging material gets } \\
\text { overheated } \\
\text { 3. Formation of cracks and intermetallic growth } \\
\text { may lead to formation of voids and delamina- } \\
\text { tion } \\
\text { 4. Outgassing is the release of a gas that was dis- } \\
\text { solved, trapped frozen or absorbed in some ma- } \\
\text { terial }\end{array}$ & $\begin{array}{l}1 \text { Do's and Don'ts session of } 15 \text { minutes to be organized daily by the supervisor } \\
\text { before each shift. } \\
\text { 2. Each employee must be trained for a period of } 7 \text { days directly under the super- } \\
\text { visor regardless of employee's experience. } \\
\text { 3.The operator should be sufficiently trained. }\end{array}$ \\
\hline $\begin{array}{l}\text { Marking } \\
\text { (MR) }\end{array}$ & 6.3 & $\begin{array}{l}\text { 1. Improper leveling } \\
\text { 2. The improper gap between capacitors pieces. } \\
\text { 3. Lack of knowledge. }\end{array}$ & $\begin{array}{l}\text { 1. Do's and Don'ts session of } 15 \text { minutes to be organized daily by the supervisor } \\
\text { before each shift. } \\
\text { 2. The operator should be sufficiently trained. } \\
\text { 3. Level must be maintained. } \\
\text { 4. Maintain the powder level setting. }\end{array}$ \\
\hline
\end{tabular}


The main objective of this research based study was to draw the attention on the issue of rejection of capacitors during the manufacturing process and revenue losses due to scraps and not delivering the orders on time. Thus, the purpose of this research work was not only to find the reasons but also to determine some feasible techniques to solve the problem to reduce the rejection of capacitors. Several brainstorming activities were organized / conducted with the heads of various departments and senior operators to reach the most feasible solution. To make the solution long lasting a new process map was formed, standardized and implemented in the warehouse department. Along with it, the implemented process was observed until it became a daily practice.

\section{Conclusion}

The aim of the research/survey was to provide the list of the root causes of capacitor rejection and suggest the most feasible solution to reduce. This study was necessary to increase the customer satisfaction, reduction in the scrap and product return. Initially a process map was documented to identify the areas of improvement. Cause and effect diagram helpes to further analyze the root causes. The monthly report of past six months of logistics department and warehouse department helped in figuring out the involvement of each root cause. Pareto Chart helped in narrowing down the root causes further. Several awareness and group discussion with logistics heads, warehouse heads and senior operators enabled the formulation of improved solutions and helped in the creation of new process map. The purpose of the study was to identify the reason for the rejection in capacitor during manufacturing. Researchers and Academicians may use this study to continue the research to find out the other types of defects. This research also provides the scope for designing the methodology for solving the problem of capacitor rejection.

\section{References}

Awaj, Y. M., Singh, A. P., \& Amedie, W. Y. (2013). Quality improvement using statistical process control tools in glass bottles manufacturing company. International Journal for Quality Research, 7(1).

Deshmukh, S. V., \& Chavan, A. (2012). Six Sigma and SMEs: a critical review of literature. International Journal of Lean Six Sigma, 3(2), 157-167.

De Mast, J., \& Lokkerbol, J. (2012). An analysis of the Six Sigma DMAIC method from the perspective of problem solving. International Journal of Production Economics, 139(2), 604-614.

Erbiyik, H., \& Saru, M. (2015). Six Sigma Implementations in Supply Chain: An Application for an Automotive Subsidiary Industry in Bursa in Turkey. Procedia-Social and Behavioral Sciences, 195, 2556-2565.

Fan, J., Qian, C., Yung, K. C., Fan, X., Zhang, G. Q., \& Pecht, M. (2015). Optimal design of life testing for high-brightness white LEDs using the six sigma DMAIC approach. IEEE Trans. Device Material Reliability, 15, 576-587.

Gupta, K., \& Kumar, G. (2014, October). Six Sigma application in warehouse for damaged bags: a case study. In Reliability, Infocom Technologies and Optimization (ICRITO)(Trends and Future Directions), $20143 \mathrm{rd}$ International Conference on (pp. 1-6). IEEE.

Gupta, K., \& Garg, M. (2014). Six sigma application in ACP sheet damage problem: A case study. Proceedings of 3rd International Conference on Reliability, Infocom Technologies and Optimization, $1-5$.

Ganguly, K. (2012). Improvement process for rolling mill through the DMAIC six sigma approach. International Journal for Quality Research, 6(3), 221-231.

Jirasukprasert, P., Arturo Garza-Reyes, J., Kumar, V., \& K. Lim, M. (2014). A Six Sigma and DMAIC application for the reduction of defects in a rubber gloves manufacturing process. International Journal of Lean Six Sigma, 5(1), 2-21. 
Kuptasthien, N., \& Boonsompong, T. (2011, September). Reduction of tombstone capacitor problem by Six Sigma technique: A case study of printed circuit cable assembly line. In Quality and Reliability (ICQR), 2011 IEEE International Conference on (pp. 546-550). IEEE.

Kaushik, P., \& Khanduja, D. (2009). Application of Six Sigma DMAIC methodology in thermal power plants: A case study. Total Quality Management, 20(2), 197-207.

Matathil, A., Ganapathi, K. N., \& Ramachandran, K. (2012). Reduction of Scrap in an Electronic Assembly Line Using DMAIC Approach. SASTECH Journal, 11(2).

More, S. S., \& Pawar, M. S. (2015, February). Implementation of Six Sigma with ISO in the Indian textile industry for improvement in performance. In Technologies for Sustainable Development (ICTSD), 2015 International Conference on (pp. 1-4). IEEE.

Ng, K. C., Chong, K. E., \& Goh, G. G. G. (2014, December). Improving Overall Equipment Effectiveness (OEE) through the six-sigma methodology in a semiconductor firm: A case study. In Industrial Engineering and Engineering Management (IEEM), 2014 IEEE International Conference on (pp. 833-837). IEEE

Prashar, A. (2014). Adoption of Six Sigma DMAIC to reduce cost of poor quality. International Journal of Productivity and Performance Management, 63(1), 103-126.

Ping Yi, T., Jeng Feng, C., Prakash, J., \& Wei Ping, L. (2012). Reducing electronic component losses in lean electronics assembly with Six Sigma approach. International Journal of Lean Six Sigma, 3(3), 206-230.

Raman, R. S., Basavaraj, Y., Prakash, A., \& Garg, A. (2017, February). Analysis of six sigma methodology in exporting manufacturing organizations and benefits derived: A review. In Computational Intelligence \& Communication Technology (CICT), 2017 3rd International Conference on (pp. 15). IEEE.

Srinivasan, K., Muthu, S., Prasad, N. K., \& Satheesh, G. (2014). Reduction of paint line defects in shock absorber through Six Sigma DMAIC phases. Procedia Engineering, 97, 1755-1764.

Simanová, L. (2015). Specific proposal of the application and implementation Six Sigma in selected processes of the furniture manufacturing. Procedia Economics and Finance, 34, 268-275.

Schroeder, R. G., Linderman, K., Liedtke, C., \& Choo, A. S. (2009). Six Sigma: Definition and underlying theory. Quality Control and Applied Statistics, 54(5), 441-445.

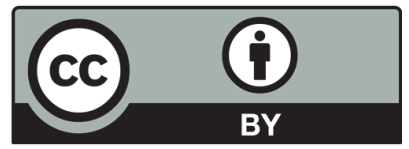

(C) 2019 by the authors; licensee Growing Science, Canada. This is an open access article distributed under the terms and conditions of the Creative Commons Attribution (CC-BY) license (http://creativecommons.org/licenses/by/4.0/). 